\title{
Study on the Value Identity of Chinese and Vietnamese Culture of Song Genius
}

\author{
Xi Chen ${ }^{1, *}$ \\ ${ }^{1}$ College of the Arts, Guangxi University, Nanning, Guangxi 530001, China \\ *Corresponding author. Email: 45856637@qq.com
}

\begin{abstract}
The geographical proximity and cultural homology make the cross-border peoples of China and Vietnam have common ground in many areas such as religion, beliefs, and living customs. A comparative study is made of the culture of Song Genius derived from the legend of Third sister liu, which is widely circulated in the Lingnan region of China, and the Song Genius culture, which has evolved from the beliefs of neighboring Vietnam's mother road, expounds the origin, connection, connotation, and future development trends between the two. Then it explains the value of the two in production and life, and further enhances the important position of the Song Genius culture in the cultural exchanges between China and Vietnam and the need to strengthen the unity and integration of the friendly nations.
\end{abstract}

\section{Keywords: China and Vietnam, song genius culture, value identity}

\section{INTRODUCTION}

Vietnam, a beautiful Southeast Asian country, is adjacent to Guangxi, Yunnan and other places in the south of China's territory, that is, the east of Indochina Peninsula. Its geographical ecology is also very similar to that of these two places. The national culture is deeply influenced by China. As a highly condensed national spirit, Vietnamese literature and art have farreaching origins with Chinese literature and art.

\section{TRACING THE HISTORICAL SOURCE OF China AND Vietnam}

The northern region of Vietnam was called "Jiaozhi" in ancient Chinese history. In the book of "Han Shu.Geography" written by Ban Gu, a famous historian in the Eastern Han Dynasty, the "Jiaozhi, Jiuzhen and Nanhai" mentioned in it are the ancient names of some places in today's Vietnam. ${ }^{1}$ These three places are adjacent to "Cangwu, Yulin and Hepu", while the latter is located in Guangxi Province.

After First Emperor of Qin Dynasty unified the six kingdoms, the northern part of Vietnam began to be the territory of the great Qin Empire. Then, in the Western

*Fund: Research on the inheritance and protection of Third sister liu's music culture in Guangxi from a new perspective", a project of humanities and social sciences of Guangxi Education Department in 2015 (project number: ky2015yb020).

Gong Yigu, (Tang) Yan Gushi Noted. "Hanshu·Geography" [M] (Middle Volume), Beijing Zhonghua Book Company, 1974, P56.
Han Dynasty, Emperor Hanwu, who had a strong military strategy, overthrew the separatist rule of the South Vietnam Empire and divided the three counties set up by the Qin Dynasty into nine. It can be said that since the Qin Dynasty, Vietnam has always been attached to China's ancient feudal rule. In 968 A.D., that is, during the Ming and Qing Dynasties, Vietnam finally broke away from the absolute rule of China's feudal dynasty and established its own dynasty. After several dynasties and generations of development and expansion, its territory continued to develop, but it was always a vassal state of China. In August 1945, Vietnam broke out the national democratic revolution, and established the Democratic Republic of Vietnam, which was changed into the Socialist Republic of Vietnam 31 years later.

Today, more than $90 \%$ of Southeast Asian countries, including Vietnam, have migrated from China. Most of them are of the same origin as the indigenous peoples in Lingnan area of China, especially in Vietnam. The main ethnic groups, such as, Vickings or Vietnamese and Annan people, are Luoyue people, one of the Baiyue people widely distributed in South and East of China in ancient times, and most of their ethnic minorities are the descendants of "Southwest Yi nationality" and "Nanman". ${ }^{2}$ The main ethnic group in Vietnam is the Jing nationality. In the hills, plateaus and valleys of the upper reaches of the Red River, there are other ethnic groups in Vietnam, such as Miao

Rui Yifu. "Chinese Nation and Vietnamese Nation", "The Collection of Sino-Vietnamese Ethnic Groups" [C] (Part 1), 1956 P79. 
nationality, Yao nationality, Dai nationality and Khmer nationality, which are similar to China. It is a multiethnic intergrowth country.

\section{INTERCULTURAL COMMUNICATION BETWEEN CHINA AND VIETNAM}

Some ethnic minorities in China and Vietnam still have a lot of ancient Luoyue heritage. Among them, Zhuang nationality in Guangxi and Tay nationality and Nung nationality in Vietnam are known to be the closest cross-border ethnic groups. Tay nationality and Nung nationality are large-scale ethnic minorities in Vietnam. They have been living next to Zhuang compatriots, in the border between China and Vietnam. There are similarities in language, belief and living customs among the nationalities with same root and same origin. The specific performance can be summarized from the following four aspects:

\section{A. Religious belief and leader worship}

The religious beliefs in Vietnam are similar to those in China, including Buddhism, Taoism and the local Gao Dai religion in the southeast peninsula. Among them, Taoism in China has the greatest impact on the religious beliefs of the Vietnamese people and is widely accepted. There is no clear statement on the time when Taoism was introduced into Vietnam. It is only known that it was around the turn of the 2nd and 3rd century AD. Taoist secular gods are the gods of this religion, such as Guan Gong and the Kitchen god, which are also popular in many places in Vietnam. At the same time, the Tay nationality and Nung nationality in Vietnam and the Zhuang nationality in China all share the same plot of leader worship. For example, there are heroic deeds of Nung Zhigao, a hero of Zhuang nationality in the Northern Song Dynasty. In Jingxi county and Tiandeng county of Guangxi, it is widely spread in other places. In Jingxi and Tiandeng counties, there are Nung Zhigao temples built by their descendants in Jingxi and Tiandeng counties. To commemorate this, there is also a Nung Zhigao temple with good attendance built on Bama mountain in Vietnam, with the inscription "本庙农志高大王将君之位" (temporary memorial tablet of Nong Zhigao). In addition, Vietnamese people will build temples for famous historical and cultural celebrities, such as "Bentou Temple" for sacrificing Ma Yuan, the founding General of the Eastern Han Dynasty, and "Guandi Temple" for worshiping Guan Gong, the martial Saint, while people in the coastal areas are more keen on building "Tin Hau Temple", which is the "Mazu" believed by Chaoshan to protect the navigation safety.

\section{B. Language}

In terms of pronunciation, words, sentence patterns and even modal particles, the Tay nationality, Nung nationality and Zhuang nationality in Vietnam have the same characteristics in language and culture. In Vietnam, the languages of Tay nationality, Nung nationality and Dai nationality (part of them) belong to the Tai-Kadai language family as well as those of the Zhuang Nationality in Guangxi and the Dai nationality in Jinping, Yunnan Province. And it has a very obvious Chinese characteristic in the grammar. As early as the end of the 19th century, some European and American scholars proposed that the Zhuang-Dong dialects of Vietnam, Thailand, Myanmar and other countries were of the same origin. Based on this, the ethnic minorities who used these languages were all the ethnic groups separated from the ancient Luoyue nationality in a certain historical period. Under the influence of Han culture, ${ }^{3}$ Tay nationality and Nung nationality created " 喃" (nan), which is almost the same as the vernacular character of the nations and ancient Zhuang nationality, to recite poems and even compose their own traditional narrative poems. Before the boundary line between China and Vietnam was clear in the 11th century, the language and characters of Tay nationality and Nung nationality (now called Tay-Nung nationality by the Vietnamese government) were the same as those of the ancient Zhuang people in China, that is, the creators of Luoyue culture. There was no barrier to the communication between the two sides, and the grammar mostly adopted the Han grammar, so it was almost impossible to distinguish the differences between their languages and cultures.

\section{Diet}

In terms of diet, the most able to reflect the similarities between the two is the five-color glutinous rice. Five-color glutinous rice is one of the products of rice culture, also known as colorful rice or Qingjing rice. It is a necessary food for the traditional major festivals of Lingnan ethnic minorities (such as March 3, May 5, Huapo Festival, etc.). In the Guangxi Zhuang Autonomous Region, cooking glutinous rice in five colors has become a necessary activity for every family every year on March 3 and the Qingming Festival. This entrusts people's good wishes, with a hope of good weather and bumper harvest in the new year. In addition, the rice will be divided into five bowls, with a red egg in the middle of each bowl to show good luck. On the Qingming Festival, the Zhuang people also use five-color glutinous rice as a sacrifice to commemorate their relatives and express their grief. Similarly, the customs of the Tay nationality in northern Vietnam are quite popular. Even its pronunciation is the same as that of Yongning adverbial ("Ngaizndangq", similar to "Yalang"), which means "five colors and five elements". In addition to white, there is glutinous rice in

Wu Sanqing, Chen Yiyuan. "Proceedings of the International Academic Conference on East Asian Chinese Literature and Folk Culture" [C], Taipei Yuexue Bureau, 1981, P56. 
four colors, namely red, yellow, green and purple, which is dyed with four different plant pigments. In addition to entertaining distinguished guests, it is also an important food for offering sacrifices to ancestors, offering sacrifices to gods and celebrating witchcraft ceremonies.

\section{Motherhood belief and goddess worship}

Both China and Vietnam have the custom of respecting Huapo, who is the God in charge of fertility in the eyes of Zhuang nationality, Tay nationality and Nung nationality. Whether a woman can get pregnant successfully depends on whether Huapo is willing to give her flowers. In addition, Huapo is also the patron saint of young children. In order to ensure safety or give birth to a noble son, people will offer sacrifices to Huapo on the first and fifteenth day of the lunar month. There are different groups of "Huapo Festival" for Zhuang Nationality in China and Tay-nung nationality in Vietnam. Its solemnity is equivalent to the "March 3rd" and Qingming Festival of Zhuang nationality every year, which is to be solemnly sacrificed and celebrated.

In some ethnic minorities in Vietnam, there is also a belief in motherhood, which worships mother as the highest belief, and believes that mother is the greatest in nature, and she protects people's health, safety and longevity. On the basis of this belief in motherhood, there are many external forms of expression, such as some singing arts and folk plastic arts. In Vietnam sites of the late Paleolithic age, some small Ivory stone statues have been unearthed, most of which have large chest and broad pelvis, showing maternal brilliance.

In Vietnam, the oldest belief similar to China belongs to the belief of Nvwa. In some rural areas of Vietnam, there are Sixiang Nvwa Temple or simple Nvwa temple. The worship of Nvwa embodies the most primitive belief in reproduction. Based on this, "mother" has naturally become the "Mu God" in the minds of Vietnamese people to create all things in the universe.

In the process of blending with foreign culture, Vietnam's national culture has been constantly enriched and improved. The mythological elements in ancient Chinese culture and the persistent and brave female images in ancient China in the long history have been absorbed into Vietnamese culture and become the prototype and support of its culture. The primitive female worship culture originated from reproductive worship in Vietnam has been upgraded to a higher level of goddess worship, which is integrated with the Chinese Goddess culture, and exudes the common spirit of cross-border ethnic groups of the two countries.

\section{VAlUe IDENTIFICATION OF CHINESE AND VIETNAMESE CULTURE OF SONG GENIUS}

\section{A. The origin of song genius culture}

According to Sun Fanggui's "Biography of Third sister liu", the original name of the song genius was Liu Sanmei, and his grandfather was Liu Chenzhi of Miao nationality. She was born in the fifth year of Shenlong emperor of Tang Dynasty. Third sister liu has been known as a song genius in the Ming Dynasty. ${ }^{4}$ It is said that her grandfather met a fairy in Tiantai Mountain. According to this, she was called "song genius". According to the book 5 "Yudi Jisheng . Sanmei Mountain" by Wang Xiangzhi, a geographer in the Southern Song Dynasty, there is a detailed account of the legend of the song genius. It is said that Third sister liu and her brothers lived in Zhongjian village, along the Zhongjian river, Luocheng, Guangxi, and she was called Third sister liu because of their third child. She is famous for the innocent and elegant, hard-working, kind-hearted, and good at singing. Therefore, she was chosen as a concubine by Mo Huairen, the rich man of Mo Village. According to the local custom, Mo selected three people to sing to Third sister liu, but they were all defeated. Third sister liu drifted to Liuzhou and Qixingyan of Guizhou Province. She sang for seven days and seven nights, and finally became yellowbird, flying together with their lovers. The legend of Third sister liu is widely spread. There are similar legends of Third sister liu in the whole Lingnan region, including Guilin, Liuzhou, Gongcheng, Fusui and other cities (counties) in Guangxi, as well as that in the minority areas of Hunan, Guangdong, Yunnan and Guizhou. In the process of spreading the story, the legend of Third sister liu has become more and more colorful with the continuous description and enrichment of people of all nationalities. After the founding of China, especially after the founding of Guangxi Zhuang Autonomous Region, Third sister liu culture has also been valued and welcomed by the local government and the broad masses of people. In September 2001, at the seminar on Third sister liu's cultural brand, the Propaganda Department of Guangzhou District Party committee of Yizhou city established Third sister liu as a folk singer and "song genius" of Zhuang nationality in China.

The legend of song genius, as well as the songs, operas and film and television work "song genius", has inherited and promoted the unique regional culture and humanistic spirit of Guangxi, namely, beautiful and natural scenery, simple and natural good folk customs, and beautiful and moving folk songs. Only beauty and wisdom cannot make Third sister liu, a legendary figure

Li Zhunan, Luo Ergang. "Historical Materials of Third sister liu" $\{N\}$, Guangxi Daily, 1986-11-25.

Cao Tingwei. "Dictionary of Guangxi Folk Stories" [K], Guangxi Education Press, 1993 P321. 
handed down from mouth to mouth, and the national image and national spirit that she embodies are the characteristics worthy of spreading. Third sister liu is respected as the "song genius" of Zhuang people, which may be related to the matriarchal attachment complex left over from the matriarchal society in the primitive worship. It also shows the female cultural tendency of the Zhuang nationality that is good at singing and dancing and the traditional culture of respecting women. Third sister liu has become a famous artistic image in China and foreign countries, and is also a symbol of Guangxi national culture and folk song culture. It can be said that China's song genius culture refers to "Third sister liu" culture.

\section{B. The connotation of Chinese "song genius" culture}

The appellation of "song genius" embodies people's respect and worship for Third sister liu, and reflects the integrity and spirit of the whole nation. Thus, the image of Third sister liu is upgraded to the image of Guangxi, Zhuang nationality and folk song. The process of Third sister liu's transformation into the image of Guangxi, Zhuang nationality and folk song is also described. Therefore, "song genius" is the accurate positioning of Third sister liu's image. "Song genius" can not only reflect the temperament and talent of Third sister liu, but also show the cultural connotation and details.

1) Taking the national spirit as the moral": Third sister liu is a representative of the song genius culture. Her folk songs carry a large amount of human cultural information, reflect the positive and optimistic national spirit and national centripetal force, and are full of unique ideological character, psychological quality and aesthetic taste of Zhuang people. The image of song genius in "Third sister liu" is the ideal embodiment of Zhuang people's resistance to class oppression and exploitation, and it is also the perfect presentation of Zhuang people's national quality of integrity, courage, wisdom, diligence and good song.

2) Being in the form of song fair: Guangxi is a sea of folk songs. Zhuang people are fond of singing, and song fair is a symbol of Zhuang culture. Since ancient times, singing in antiphonal style, singing for competition, and the song appreciation have been the survival mode and entertainment tradition of Zhuang people from generation to generation. The reason why singing has become the characteristic of Zhuang nationality can be found in Liu Xifan's book "Lingbiao Jiman the reason why the barbarians like singing", that is, the Zhuang people think that singing is an essential activity in life. Singing can divert people from loneliness, help to seek lovers, broaden their horizons, enrich their knowledge and educate the foolish people.
${ }^{6}$ It can be seen that Zhuang people use this kind of values to examine their own values and the value functions of social and cultural activities. People who are good at singing can not only win support and fame, but also show their values of life and love to the people around them. Since the film "Third sister liu" was on the screen, it can be said that it has been admired by many people for a long time. Among them, the most eye-catching segment is the singing scene between Third sister liu and the talents. In Guangxi, the hometown of Third sister liu, similar events are held every year. Third sister liu culture is expressed in the form of song fair, which has unique and artistic charm.

3) Taking Entertainment as the root: The core reasons why the song genius culture of "Third sister liu" has never faded lie in its unique cultural connotation of entertainment and revelry. This is extremely rare in ancient Chinese legends and fairy tales. Similar to the four major love legends of the Han nationality, namely, "Cowherd and the weaving maiden", "Lady Mengjiang", "Madam White Snake" and "The Butterfly Lovers", the song genius culture of Third sister liu also shows the national spirit of the times in pursuit of freedom and resistance to oppression. The only difference is that it is based on the root of entertainment and carnival. With the help of the singing tradition and song fair culture of the Lingnan ethnic minorities, especially the Zhuang nationality, it is rooted in the natural cultural gene of advocating nature and loving freedom, and has become the symbol of entertainment and carnival in Lingnan national culture. Song genius culture fills in the heavy shackles and defects of Chinese traditional culture, which overemphasizes etiquette, suppresses personality, and overcomes self-restraint. It is a concentrated embodiment of the confrontation between popular culture and orthodox feudal culture.

\section{The performance of song genius culture in Vietnam}

The special geographical location of Vietnam and China, the ethnic homology and the special attribute of the long-term cultural penetration make the song genius culture naturally introduced into Vietnam. In addition, the motherhood and goddess belief advocated by Vietnamese people since ancient times are all based on female images, and the introduction of song genius culture is also rooted in the soil worshipped by Vietnamese local women images and germinated in this life. According to the research and analysis of famous cultural scholars, the legend of song genius is widely spread in most counties and cities of Guangxi Province, such as Guigang, Guiping, Rongxian, Cangwu,

Liu Xifan. "Lingbiao Jiman"[M]. Beijing: Commercial Press, 1934, P121. 
Mashan, Donglan, Yizhou, Liuzhou, Rongshui, Laibin, Xiangzhou, Lingchuan, Leping, etc., affecting many ethnic groups, such as Zhuang, Han, Miao, Yao and other ethnic elements, and Daxin, Qinzhou, Qingzhou, and Chongzuo which border with Vietnam are also among them.

Since ancient times, song fair is the most important form of song genius culture. It not only exists in Guangxi, but also exists in the border areas with Vietnam. Qin Guiqing's "Third sister liu" recorded the origin and geographical location of the song fair along the Sino-Vietnamese border. Zhen'an Prefecture on the Sino-Vietnamese border called the song fair "Xiang Dan", or "Dan" for short. Setting the song fair is called "Qi Dan", the site of song fair is called "Po Dan", and the date of song fair is called "Min Dan". Taking the country fair in Thành phố Cao Bằng as an example, there are two types of the date of singing fair. First, there is a fixed period and place; second, the day of Qingming Festival is the day of song fair, that is, the day of Qingming Festival is the same as that of traditional market fair. The ninth day of the first month is the song fair of Shuojiang, which is called Danxiang Shuo. Shuojiang is a traditional site of song fair in Heguang County, Thành phố Cao Bằng. It is also $\mathrm{a}$ trading point of border trade. Every fourth or ninth days is a fair day. Shuojiang is adjacent to Pingmeng street in Napo County of China. The name of Pingmeng street is Xiang'ai, that is, Pingmengai fair. The fair data is on March 3 and 8, and the song fair is on March 28. The border people of the two countries usually trade with each other in the market and exchange songs on the day of song fair. There is a Nung Zhigao temple near shuojiang. It is ceremoniously worshipped on the day of song fair, and the incense is especially prosperous. On the day of Shuojiang song fair, witches were invited to recite scriptures in the temple, and the men, women, old and young who attended the song fair were driven to worship in the temple, which became a scenery of Shuojiang song fair. On the day of Qingming Festival, the fairs in Shanglang and Xialang counties under the Chongqing government were held. If the fair period is the same as that of the Qingming Festival, this fair is song fair, and other fairs arrange song fairs in the order of each festival on the day after Qingming Festival. ${ }^{7}$

In addition, the Jing nationality, the main nationality of Vietnam, has this tradition. It is also known as "Hajie Festival", which is the biggest festival of the nation. "Ha" is the pronunciation of Vietnamese Jing language, including the meaning of "song" in Chinese. There are also various versions of folk stories in this festival. Among them, the most typical legend tells that a song genius came to the three islands of the Jing nationality in ancient times. In the name of teaching everyone to

Qin Guiqing, "Third sister Liu" [M], Nanning: Guangxi Nationalities Publishing House, 1992. sing, he encouraged and mobilized the people of Jing nationality to stand up, resist feudal oppression and fight for freedom. In memory of this song genius, people built "Hating" and regularly sang songs here, which gradually evolved into a festival. The song genius here probably refers to Third sister liu ${ }^{8}$. Hajie Festival is a traditional festival of the Jing people in the border area between China and Vietnam. It is usually celebrated in June or the tenth day of August or the fifteenth day of the first month of the lunar calendar, that is, the Lantern Festival. The festival lasts for three days, and the people stay up all night singing and dancing.

It can be seen that Vietnam's song genius culture can be basically identified as originated from China's song genius culture. Both belong to the same cultural form with the same origin and share the same form of expression - song fair. Both of them bear the local matriarchal belief and "goddess" worship complex in terms of humanistic connotation, reflecting the common national cultural connotation of the two countries: the life values of advocating freedom and liberation of nature, the social values of respecting women's social status, and the collective values of unity and cooperation and national integration. Both reach a consensus on the values of humanity, society and collective, so that the song genius culture occupy a place in the intangible cultural heritage of the traditional minority culture.

\section{THE INHERITANCE TREND OF SONG GENIUS CULTURE IN THE NEW ERA}

Third sister liu is a well-known image of "song genius" in China and foreign countries. The image has been created, spread, enriched and developed for a long time. All of these are inseparable from the accumulation and inheritance of historical culture. It is a landmark of national culture, regional culture and folk culture. Against the background of globalization, especially under the guidance of new ethnic policies such as "the Belt and Road Initiative", national integration, international exchange and cooperation advocated by China, there are different degrees of cooperation and interaction among different nationalities and neighbors. Nowadays, the pure national culture which is completely free from any culture and isolated from the outside world can hardly be seen in the long run. In the process of its historical development, song genius culture has been constantly integrated with other national cultures and the cultures of the times. From a kind of original ecological folk art which was handed down orally in the field, it has

8 Nong Xueguan. "The Story, Songs and Proverbs of the Zhuang Nationality" $[\mathrm{J}]$, contained in "Academic Exchanges in Thailand-Ethnic Research", P25, edited and printed by Guangxi University for Nationalities in May 1986. 
gradually transformed into a well-known ethnic cultural brand and become the synonym of Guangxi Province. With the increasingly frequent and close cultural exchanges between China and ASEAN, the derivation and inheritance of song genius culture will be bound to have a new posture and new charm.

\section{A. The new edition of "Third sister liu"}

At the beginning of 1960, the film "Third sister liu", which was produced by Changchun Film Studio and directed by Suli and starred by Huang Wanqiu and Liu Shilong, was popular for a time. The excellent acting skills of the actors, the beautiful scenery of Guilin mountains and rivers, and more than ten popular classic songs deeply attracted Chinese audiences in China and foreign countries and had great influences. In the 1980s, the song and dance drama "Third sister liu", directed and performed by Guangxi, made its debut in China, and then toured Southeast Asia for many times. There was an upsurge of imitating and singing Third sister liu's Ballads in Vietnam, Singapore and Thailand. In the summer of 2013, Guangxi Caidiao troupe redesigned and performed, and a large-scale color tune song and dance drama "Third sister liu" came into being. It has been touring in Thailand, Malaysia, Brunei, Cambodia and other Southeast Asian countries, and is highly sought after. Since the beginning of the 21 st century, three different versions of "Third sister liu" have been published in Guangxi alone, including color tone, dance drama and drama. Against the new historical background, Third sister liu's ballad culture has renewed its vitality. "Third sister liu" has become an ambassador of cultural exchange and cooperation between China and ASEAN. In the process of spreading "Third sister liu" to Southeast Asian countries including Vietnam, it is necessary to properly consider the local customs, the original plot and language lyrics. On the one hand, it is required to train the performers in Guangxi to speak and sing in Vietnamese. On the other hand, it is better to train Vietnamese local singers to learn and sing "Third sister liu", so as to achieve language exchange and resonance, and realize real cross-border communication.

\section{B. Cross-border song fair}

It has become the consensus of Zhuang people that "all the songs in the song fair are the folk songs of Third sister liu". The song fair of Zhuang people has become an important base for inheriting and carrying forward Third sister liu's song genius culture. However, with the changes of the times and the urbanization, the song fair will also face the same cruel situation that all intangible cultural heritage faces. The scenery of traditional song fair is no longer, there are few singers, and the audiences of song fair are constantly losing. Therefore, how to save and protect the precious cultural wealth of the traditional song fair, how to develop and utilize the environment and resources reasonably according to local conditions are the common goals of modern ethnic culture and art workers.

In the new historical period, the development, protection and inheritance of intangible cultural heritage are more arduous and meaningful. Intangible cultural heritage workers should not only rescue the original cross-border song fair, but also vigorously promote and expand these national arts. The original cross-border song fairs along the Sino-Vietnamese border include: Jiuzhou song fair, Huadong song fair and Ludong song fair in Jingxi, Tongzhong song fair and Naliang song fair in Fangchenggang, Shangshi song fair and Xiashi song fair in Pingxiang, Fubo song fair in Dongxing and, Jinlong Nungdong Festival and Xiadong song fair in Longzhou. These original crossborder song fairs should be implemented and improved as demonstration sites to bring the old with the new, so as to drive more cross-border song fairs in the surrounding areas to join. After forming a scale, they can hold song fair competitions or social activities on holidays (such as "March 3rd" in Zhuang township) to promote mutual development.

In the new historical period, the traditional local song fair has been unable to adapt to the current needs of intangible cultural heritage due to its geographical and singing mode limitations. In the inheritance of traditional intangible cultural heritage, it is necessary to learn the means of new market or science and technology, such as singing fair souvenir (a ball made of strips of silk, Zhuang brocade, agricultural and sideline products, etc.), mobile phones, network (Tencent, Tik Tok, short video, etc.) for marketing promotion. It also can shoot song fair documentary and interview song fair entertainers. It is better to use multimedia means to rescue and protect the heritage of traditional culture, which is the necessary way in the new period of development.

The research on the value identification of Vietnamese song genius culture is based on a mode of seeking for the root of culture, which has become a new trend of thought and a new research direction against modernity under the trend of globalization. With the help of the construction of China-ASEAN Free Trade Area and Nanning International Folk Song Art Festival, the cross-border and cross-cultural integration of ethnic minorities in the Sino-Vietnamese border has been widely concerned by the academic community. Based on this, it is of great academic value and practical significance to strengthen the comparative study of cultural anthropology, literature and art between the two countries, investigate the cultural origins in the history of China and foreign countries, and save and protect the intangible cultural heritage of mankind. 


\section{CONCLUSION}

The cross-border and cross-cultural integration of ethnic minorities in Chinese and Vietnamese border areas has been widely concerned by the academic community. Based on this, it is of great academic value and practical significance to strengthen the comparative study of cultural anthropology, literature and art between the two countries, investigate the cultural origins in the history of China and foreign countries, and save and protect the intangible cultural heritage of mankind. This paper takes the song genius culture as the starting point and makes a comparative study on the song genius culture of ethnic minorities in China and Vietnam. Through interviews and investigation, it sorts out and compares the core contents of song genius culture between China and Vietnam, including legends, ballads and lyrics, song fair culture, and communication channels. It also integrates the ideological connotation of the new era, and boldly relies on the construction of China-ASEAN Free Trade Area and Nanning International Folk Song Art Festival, so that song genius culture can be spread across regions and countries. Conforming to the concept of development of "the Belt and Road initiative" in the new era is an important embodiment of the concept of development of the nation against the background of the new era. It not only plays a positive role in rescuing and protecting China's fine traditional culture, but also gives a great boost to strengthening ethnic integration, promoting ethnic unity and carrying forward ethnic culture.

\section{References}

[1] Huang Yan, Yi Qizhi. On the Inheritance of Luoyue Culture between Chinese Zhuangzu and Vietnamese Tay and Nung Ethinic Groups: The Third Paper of the Serial Researches on Luoyue Culture [J], Journal of Guangxi Teachers Education University, 2017 (03). (in Chinese)

[2] Huang Ling. A Comparative Study of Cross-border Ethnic Literature between China and Vietnam - Taking Folk Narrative Literature as an Example [J], Guangxi Normal University, 2011 (05). (in Chinese)

[3] Huang Yunfang. Viewing the construction of "song genius" of Third sister Liu from the perspective of folk culture [J], Journal of Guangxi Radio and TV University, 2015 (09). (in Chinese)

[4] He Mingzhi. The cultural root-seeking phenomenon and cultural soft power in folk songs-Taking the Dan song on the SinoVietnamese border as an example, Journal of The Guangxi Institute of Socialism [J], 2015 (02). (in Chinese)

[5] Pan Qixu. Third sister liu is a typical artistic example of singing sacredness, Journal of Baise University [J], 2008 (10). (in Chinese)

[6] Huang Guiqiu. The REVIVAL AND RECONSRTUCTION OF THE CULTURE OF SINGING FAIR OF THE ZHUANG IN THE SINO-VIETNAMESE BORDER AREAS, Study of Ethnics in Cuangxi [J], 2016 (05). (in Chinese)

[7] Huang Guiqiu. Read and Explan the Anthropology of Liu Sanjie' s Culture, Journal of Hechi University [J], 2008 (01). (in Chinese)
[8] Ren Xubin. Semiotic research on the image of Liu Sanjie [D], Study of Ethnics in Cuangxi, 2008 (2). (in Chinese) 